\title{
Stem cell therapy in autism: recent insights
}

This article was published in the following Dove Press journal: Stem Cells and Cloning:Advances and Applications

\author{
Dario Siniscalco' \\ Suresh Kannan ${ }^{2}$ \\ Neomar Semprún- \\ Hernández ${ }^{3}$ \\ Adrien A Eshraghi ${ }^{4}$ \\ Anna Lisa Brigida ${ }^{5}$ \\ Nicola Antonucci ${ }^{6}$ \\ 'Department of Experimental \\ Medicine, University of Campania, \\ Napoli, Italy; ${ }^{2}$ Department of \\ Biomedical Sciences, Sri Ramachandra \\ Institute of Higher Education and \\ Research, Chennai, Tamil Nadu, \\ India; ${ }^{3}$ Research Division, Autism \\ Immunology Unit of Maracaibo, \\ Catedra libre de Autismo, Universidad \\ del Zulia, Maracaibo, Venezuela; \\ ${ }^{4}$ Department of Otolaryngology, \\ Hearing Research and Cochlear \\ Implant Laboratory, University of \\ Miami Miller School of Medicine, \\ Miami, FL, USA; ${ }^{5}$ Italian Group for \\ Studying Autism - GISA, Brescia, \\ Italy; ${ }^{6}$ Biomedical Centre for Autism \\ Research and Treatment, Bari, Italy
}

Correspondence: Dario Siniscalco Department of Experimental Medicine, University of Campania, Via S. Maria di Costantinopoli 16,80138 Naples, Italy $\mathrm{Tel}+39815665880$

Email dariosin@uab.edu

\begin{abstract}
Autism spectrum disorders (ASDs) are characterized by core domains: persistent deficits in social communication and interaction; restricted, repetitive patterns of behavior, interests, or activities. ASDs comprise heterogeneous and complex neurodevelopmental pathologies with well-defined inflammatory conditions and immune system dysfunction. Due to neurobiologic changes underlying ASD development, cell-based therapies have been proposed and applied to ASDs. Indeed, stem cells show specific immunologic properties, which make them promising candidates in ASD treatment. This comprehensive up-to-date review focuses on ASD cellular/ molecular abnormalities, potentially useful stem cell types, animal models, and current clinical trials on the use of stem cells in treating autism. Limitations are also discussed.
\end{abstract}

Keywords: autism spectrum disorder, stem cell, cell therapy, immune dysfunction

\section{Autism spectrum disorders (ASDs)}

ASDs are very interesting neurodevelopmental disorders for the medical and scientific community, because of their multifactorial nature and many different explanations for their clinical heterogeneity. ${ }^{1}$ ASD patients display highly diverse groups of disorders with wide variation in symptoms, intellectual level, severity, and functional disability. ${ }^{2}$ The variation is due in part to its multifactorial origin that leads ASD to be a neurogenetic clinical entity ${ }^{3,4}$ with gastrointestinal, ${ }^{5,6}$ immunologic, ${ }^{7,8}$ and metabolic implications ${ }^{9}$ that begin in the womb. ASDs are multistage, progressive disorders of brain development and synapse connections, spanning nearly all of pre- and postnatal life. ${ }^{1}$ ASD starts on the first embryonic stages with disruption of cell proliferation and differentiation, which leads to a series of sequential events like neural migration, laminar disorganization, altered neuron maturation, neurite outgrowth, problems of synaptogenesis, and reduced neural network functioning. ${ }^{1}$

ASD affects more than $1 \%$ of the general population (1:59 subjects $)^{10}$ and are characterized by two core symptoms: the first one is impaired social communication, and the second situation is restricted, repetitive types of behavior, interests, or activities. However, the biggest problem in autism is triggered by associated symptoms such as irritability, anxiety, aggression, compulsions, mood lability, gastrointestinal issues, depression, and sleep disorders. ${ }^{11}$ On the basis of the core and associated symptoms, autism is diagnosed through observational and psychometric tests; therefore, the clinical diagnosis is made based on the presence or absence of core behaviors. The Diagnostic and Statistical Manual of Mental Disorders is conventionally used as a gold standard for autism diagnosis. ${ }^{12}$ submit your manuscript $\mid$ www.dovepress.com 
However, the neurometabolic differences of autism lead us to look for biologic markers that respond to a correct, precise, and concise diagnosis. ${ }^{13}$ These biologic markers should be detected early during pregnancy, because the pathogenesis of ASD is not set at one point in time and does not reside in one process, but rather is a cascade of pre- and postnatal pathogenic processes in the vast majority of ASD toddlers. ${ }^{1}$

The treatment of ASD is variable and multimodal. It is composed of conventional therapies, such as social skills training, early intensive behavior therapy, applied behavior analysis, speech therapy, occupational therapy, together with psychotropic drugs, ${ }^{14}$ transcranial magnetic stimulation, ${ }^{15}$ and alternative treatments, which include hyperbaric oxygen treatment, ${ }^{16}$ music therapy, and cognitive and social behavioral therapy. ${ }^{17}$ Hormonal therapies with oxytocyin have also shown some promises in improving central ASD symptoms. ${ }^{18}$ The use of vitamins, herbals, essential oils, and nutritional supplements ${ }^{19,20}$ and conventional therapies have some effect in symptomatic improvement in ASD, though additional studies are needed to confirm these benefits. Developing novel therapies may prove to be the ultimate intervention for sustained improvement of symptoms in ASD. ${ }^{17}$ Among the new therapies available, there are the gene therapy and stem cell therapy, which have great potential for treating ASD. ${ }^{21,22}$ The redesign of brain architecture, generated from reprogrammed somatic cells isolated from living patients, provides new insights into the understanding of autism and thus reverses or ameliorates the symptoms of disorder. Here, we discuss recent advances in the use of stem cells as a therapy of ASD, as well as its limitations, implications, and future prospects.

\section{Stem cells for neurologic diseases}

The possibility to face neurologic diseases and ASD in particular with stem cell application is described in this section.

Neurologic diseases are usually irreversible as a result of slow and limited neurogenesis in the brain. ${ }^{23}$ Therefore, based on the regenerative capacity of stem cells, transplantation therapies of various stem cells have been tested in basic research with animal models, and preclinical and clinical trials, and many have shown great prospects and therapeutic promises. ${ }^{23}$ Comparative studies have been raised to understand nature, properties, and number of donor stem cells, the delivery mode, and the selection of proper patient populations that may benefit from cell-based therapies. ${ }^{24}$

However, many times these aspects do not allow to predict why there is no suitable animal model for the study of certain diseases of neurologic development. Animal models of complex immuno-gastrometabolic phenomena, such as the ASD, are difficult to validate. The reprogramming of somatic cells into induced pluripotent stem cells (iPSCs) could offer an alternative strategy for identifying the cellular mechanisms contributing to autism and the development and testing of many new treatment options. ${ }^{25}$ This aspect will be defined at the end of this review because it contains the key to success of the therapy of stem cells in autism.

\section{Mechanisms underlying therapeutic effect}

At least two key-action mechanisms of stem cells could be useful for ASD therapy: paracrine effect (the secretome tool: cytokines, chemokines, and growth factors released by stem cells and responsible of repair/restoration of injured tissues) and immunomodulatory properties. ${ }^{22}$ ASDs show immune system abnormalities and strong proinflammatory cytokine production. ${ }^{26,27}$ ASD subjects show an imbalance in innate and adaptive immunity, as $\mathrm{CD}^{+}, \mathrm{CD}^{+}$, and $\mathrm{CD}^{+}$ $\mathrm{T}$ cells, as well as natural killer (NK) cells, are altered. ${ }^{27}$ Immune alterations in ASDs are still confirmed by abnormal monocyte and macrophage responses, which overproduce proinflammatory IL- $1 \beta$ cytokine and show several altered molecular systems resulting in long-term immune alterations. ${ }^{8,26,28-30}$ The immune modulatory capacity of stem cells could restore these ASD-immune alterations. Stem cells are able to strongly inhibit $\mathrm{CD}^{+}$and $\mathrm{CD}^{+} \mathrm{T}$ lymphocytes and NK cell overactivation and proliferation by inhibiting proinflammatory tumor necrosis factor alpha and interferon gamma molecules and increasing anti-inflammatory IL-10 levels. ${ }^{31}$ This fact is confirmed by an animal model of autism, in which stem cells, once transplanted, were able to increase anti-inflammatory cytokine production (detailed in Stem cells and autism: animal models section). The ability to modulate the immune system by stem cells is mediated via soluble factors released by stem cells under local chemical environment signaling. ${ }^{32}$ Another proposed mechanism by which stem cells are able to address the ASD-mediated immune and inflammatory abnormalities is the cell-to-cell contact activation mechanism, by which stem cells are able to switch proinflammatory cells to antiinflammatory ones. ${ }^{22,32}$

Table 1 summarizes the harmful processes of ASD that could be contrasted by stem cell's own capacities. The next section will explain the potential use of specific stem cell types for ASD. 
Table I Diagrammatic representation of different stem cells and related sources for the treatment of autism and their mechanisms of action

\begin{tabular}{|l|l|l|}
\hline Type of stem cells & Source & Mechanism of action \\
\hline Fetal stem cells & $\begin{array}{l}\text { Fetus, fetal blood, placenta, amniotic } \\
\text { membrane, amniotic fluid, umbilical cord }\end{array}$ & $\begin{array}{l}\text { Secretion of neurotrophic factors } \\
\text { Immunomodulatory capacities } \\
\text { Suppression of proinflammatory processes }\end{array}$ \\
\hline Mesenchymal stem cells & Bone marrow, umbilical cord & $\begin{array}{l}\text { Paracrine secretion of several anti-inflammatory and } \\
\text { survival-promoting molecules (ie, VEGF, HGF, BDNF, } \\
\text { NGF) } \\
\text { Neuroprotective effects } \\
\text { Hypoimmunogenic and immunosuppressive properties }\end{array}$ \\
\hline Neural stem cells & $\begin{array}{l}\text { Secretion of neurotrophic factors } \\
\text { Maintenance of homeostasis } \\
\text { ventricles and subgranular zone of } \\
\text { hippocampus) }\end{array}$ & $\begin{array}{l}\text { Secretion of trophic factors } \\
\text { Immunosuppressive and hypoimmunogenic effects }\end{array}$ \\
\hline Adipo-derived stem cells & Adipose tissue & $\begin{array}{l}\text { In vitro growth capacity } \\
\text { Low immunogenicity and immunomodulation properties }\end{array}$ \\
\hline $\begin{array}{l}\text { Umbilical cord- and amniotic } \\
\text { fluid-derived stem cells }\end{array}$ & Umbilical cord, placenta, amniotic fluid & Paracrine activity \\
\hline Hematopoietic stem cells & Blood, bone marrow, umbilical cord & Differentiation capacity \\
\hline Induced pluripotent stem cells & Any cell type & \\
\hline
\end{tabular}

Note: Homing and mobility capacities are common for all the stem cell types.

Abbreviations: VEGF, vascular endothelial growth factor; HGF, hepatocyte growth factor; BDNF, brain-derived neurotrophic factor; NGF, nerve growth factor.

\section{Stem cell types}

Several types of stem cells have been described. The following section shows each type with potential use for the treatment of ASDs.

\section{Fetal stem cells (FSCs)}

FSCs are found at various stages of human development and can be isolated from various somatic organs of fetus, fetal blood, and a variety of extraembryonic sources like placenta, amniotic membrane, amniotic fluid, and umbilical cord. FSCs have properties that lie in between the embryonic and adult stem cells that they self-renew faster in culture, have greater differentiation potential and high engraftment rate, and do not form teratomas in vivo. ${ }^{33}$

Fetal SCs from bone marrow express pluripotent markers like Oct-4, Nanog, Rex-1, SSEA-3, SSEA-4, Tra-1-60, and Tra-1-81 and show higher telomerase activity, which makes them a preferable candidate for therapeutic applications. ${ }^{33}$ For treating neurodegenerative diseases, neural stem cells (NSCs) from different parts of the fetal brain have been explored. The fetal NSCs have the ability to self-renew and are multipotent being able to differentiate into neurons, astrocytes, and oligodendrocytes. ${ }^{34-36} \mathrm{FSCs}$ have the ability to secrete various neurotrophic and immunomodulatory factors that promote neuronal growth and suppress the action of proinflammatory cytokines that make them a potential candidate for treating ASDs and various neurodegenerative diseases. ${ }^{37}$
There are various reports on the successful use of FSCs for different neurodegenerative disorders. When the fetal NSCs were transplanted into the rat models of temporal lobe epilepsy and ischemia, they get grafted and differentiated into neurons. ${ }^{34,35}$ A clinical trial in younger human Parkinson's patients also showed promising results when dopamine neurons from fetal neural tissues were transplanted. ${ }^{36} \mathrm{An}$ open-labeled clinical trial that examined the safety and efficacy of FSCs in autistic children revealed no adverse events and a significant difference in the improvement of autistic symptoms (detailed in Stem cells and autism: animal models section). ${ }^{37}$

\section{Bone marrow-derived stem cells Mesenchymal stem cells (MSCs)}

MSCs are found in almost all the adult tissues and are characterized by their ability to adhere to plastic surface, express cell surface antigens like CD105, CD90, and CD73, not express CD34, CD45, CD14 or CD11b, CD79 $\alpha$ or CD19, and HLA-DR, and differentiate into osteoblasts, chondroblasts, and adipocytes in culture. ${ }^{38}$ Apart from these minimal characteristics, MSCs have wider properties like their ability for rapid proliferation, differentiation into cell types of endodermal and ectodermal origins, secretions of various tropic factors, and immunomodulatory action, which make them a preferable candidate for cellular therapies..$^{39,40}$ 
The paracrine secretion and immunomodulatory properties of MSCs make them a potential candidate for treating ASDs. ${ }^{41}$ Cultured MSCs secrete various neurotrophic factors including vascular endothelial growth factor (VEGF), hepatocyte growth factor, brain-derived neurotrophic factor (BDNF), and nerve growth factor and exhibit neuroprotective effects. ${ }^{42}$ MSCs are also hypoimmunogenic and have immunosuppressive properties that they do not express costimulatory molecules such as CD80, CD86, or CD40 and express low levels of MHC class I molecules. ${ }^{43,44}$ Different mechanisms were hypothesized for using MSCs for treating ASDs that include inducing plasticity, secretion of antiinflammatory and survival-promoting factors, and engrafting into neural network. ${ }^{45}$

Also, in vivo, in different animal models of neurodegeneration, MSCs exert neuroprotection mainly by secretion of various neurotrophic and immunomodulatory factors, thus facilitating the recruitment of endogenous stem cells to promote regeneration and by downregulating $\mathrm{T}$ cells, $\mathrm{B}$ cells, and NK cells of immune system. ${ }^{46}$ Owing to these properties, MSCs were highly preferred candidates for clinical trials for various neurologic diseases. Clinical trials using MSCs are ongoing for diseases like multiple sclerosis (MS), stroke, Parkinson's disease (PD), Huntington's disease (HD), Alzheimer's disease (AD), and systemic autoimmune diseases. ${ }^{47}$ For ASDs, several studies using stem cells have been conducted in humans (detailed in Stem cells and autism: animal models section); a study by Lv et al analyzed the safety and efficacy of using human cord blood mononuclear cells (CBMNCs) and umbilical cord-derived mesenchymal stem cells (UCMSCs) in treating children with autism. ${ }^{48}$ They reported safe and statistically significant improvements in the Childhood Autism Rating Scale (CARS), Clinical Global Impression (CGI) scale, and Aberrant Behavior Checklist $(\mathrm{ABC})$ in the children treated combinedly with CBMNCs and UCMSCs when compared to the control group.

\section{Adipo-stem cells}

Stem cells can also be isolated from different adipose tissues in the body in a minimally invasive manner and are termed as adipose-derived stem cells (ASCs). Similar to MSCs, ASCs are plastic adherent, express CD90, CD105, CD73, CD44, and CD166, lack the expression of CD45 and CD34, and have the ability to differentiate into cells of all three germ layers. ${ }^{49,50}$

Along with being multipotent, ASCs secrete various trophic factors and are immunosuppressive and hypoimmunogenic, making them an attractive candidate for cellular therapies. ASCs have been used in various clinical trials targeting a wide range of indications ranging from immune disorders, myocardial infarction, bone defects, and neurodegenerative diseases. Although no reports have been found on the use of ASCs for treating ASDs, ASCs have been proven effective in other neurologic preclinical models, as in the mouse model of middle cerebral artery occlusion, human ASCs partially rescue the stroke syndromes by forming new neurons and blood vessels and increasing the viability of endogenous neurons. ${ }^{51}$

\section{Umbilical cord- and amniotic fluid- derived stem cells}

Umbilical cord and placenta also offer a good source of stem cells..$^{22}$ These stem cells offer strong potential therapeutical applications and display mesenchymal characteristics. ${ }^{52}$ The Wharton Jelly of the umbilical cord and the amniotic fluid are other sources of stem cells possessing high in vitro growth capacity and low immunogenicity and immunomodulation properties, expressing the typical antigen profile of MSCs. ${ }^{53,54}$ These cells from perinatal, extraembryonic tissue have potential for future applications in ASDs. ${ }^{22}$ There are no ethical controversy and risk of teratoma formation, and they could also be used for autologous transplantation after banking in later stages of life. ${ }^{55}$

\section{NSCs}

NSCs are found in the fetal and adult human brain and have the potential for extensive proliferation and differentiation into three major cell types of the nervous system, the neurons, astrocytes, and oligodentrocytes. ${ }^{56}$ The NSCs that can be extracted from two major regions of the brain, namely, the subventricular zone of lateral ventricles and subgranular zone of hippocampus, can be cultured. ${ }^{57,58}$ The culture-expanded NSCs are multipotent, have the ability to differentiate into various neuronal cell types, secrete neurotrophic factors, integrate into neural tissue, maintain homeostasis, and are neuroprotective, making them an ideal candidate for treating ASDs. Indeed, impairments in excitatory and inhibitory cortical neurons lead to minicolumn structure abnormalities in ASDs. ${ }^{56}$ Synaptic-related genes show multiple rare variants in some ASD subjects. ${ }^{59}$ Given that, transplantation of NSCs could be effective in ASDs, as transplanted cells can promote neural tissue repair and homeostasis through integration in damaged areas and secretion of factors that enhance brain repair and plasticity. ${ }^{60}$ The definitive use of NSCs for clinical applications in neurodegenerative diseases still requires addressing some critical issues: autologous reliable source of 
sufficient amount of stem cells needs to be identified; posttransplanted neural plasticity and differentiation, if any, must be further defined. ${ }^{60}$ However, though NSCs have been used in various preclinical and clinical studies against different neurologic conditions like $\mathrm{PD}, \mathrm{HD}, \mathrm{AD}$, amyotrophic lateral sclerosis (ALS), MS, stroke, and spinal cord injury (SCI), the outcome is not definitive as expected and is hindered by several points to be further elucidated: the absence of homogenous cell population, stability, and long-term survival of neurons after transplantation. ${ }^{61,62}$

Different methods have been tried to enhance the capabilities of NSCs, like immortalizing the NSCs by gene manipulation techniques to create a homogenous, long-surviving cell that is capable of differentiating into neurons and glial cells when transplanted into normal or damaged brain. ${ }^{58}$

\section{Hematopoietic stem cells (HSCs)}

HSCs are mainly resident in bone marrow and also in blood and umbilical cord. Specific cluster of differentiation markers characterize them (CD34, CD59, CD117, CD133, CD164). ${ }^{63}$ Self-renewal, multipotency, and homing/mobility activities are very high. This type of stem cells is able to differentiate in myeloid and lymphoid lineages. Their paracrine activity, releasing bioactive molecules, and their ability to quickly traffic to the site of inflammation gained them a lot of attention for their use in ASD therapy. ${ }^{63}$ Several clinical trials have been performed with the use of CD34+ stem cells in autism (detailed in Stem cells and autism: animal models section).

\section{iPSCs: the new frontier for cell therapy}

iPSCs could represent a novel tool for ASD therapy.

iPSCs are relatively new type of stem cells that are reprogrammed from any cell type of the body by ectopic expression of different transcriptional factors originally by using integrating vectors like retroviruses and lentiviruses. The iPSCs derived by these methods pose risk of insertional mutagenesis and make them unsafe for therapeutic applications. To overcome this obstacle, various new methods like use of small molecules, sendai virus, adenovirus, RNA molecules synthesized by plasmids, and recombinant proteins have evolved to create integration-free iPSCs. ${ }^{64}$ The iPSCs derived from different methods have the characteristics similar to that of embryonic stem cells, being able to self-renew, express stem cell markers, and differentiate into the cell of all the three germ layers except the cells in extra-embryonic tissue. The main advantage of iPSCs over the ES cells is their easy way of derivation from any cell type without the need for embryos and that they serve as an unlimited cell source for autologous therapy. iPSCs derived from the donors have many applications apart from being used for regenerative therapies, and the patient-specific iPSCs are used in disease modeling, toxicity testing, and drug screening studies. ${ }^{64}$

Disease-specific iPSCs derived from patients serve as an infinite source for drug testing studies. A wide range of iPSCs are produced from patients suffering from unifactorial and multifactorial diseases ranging from adenosine deaminase deficiency-related severe combined immunodeficiency, PD, HD, ALS, Down syndrome, type 1 diabetes, Duchenne muscular dystrophy, spinal muscular atrophy, and $\beta$-thalassemia ${ }^{65}$ that serve as a model for disease and for drug testing on them.

With regard to therapeutic usage, iPSCs are viewed as a potential candidate for treating various disorders. The proof to substantiate the use of iPSCs for clinics comes from various in vitro and in vivo preclinical trials. In in vitro, iPSCs can be made to differentiate into various cell types like dopamine and motor neurons, dendritic cells, functional cardiomyocytes, macrophages, hepatocytes, and hematopoietic and endothelial cells. ${ }^{66}$ There are several in vivo studies that prove the efficiency of iPSCs in treating neurodegenerative disorders, cardiovascular disease, and sickle cell anemia. For example, in contusive SCI model in nonobese diabetic severe combined immunodeficient mice, injection of neurospheres derived from human iPSCs leads to recovery of locomotor function without formation of any tumors. ${ }^{67}$ The differentiation capabilities of injected neurospheres into neurons, astrocytes, and oligodendrocytes along with induction of angiogenesis, axonal regeneration, and localcircuitry reconstruction may contribute to the recovery in SCI model. ${ }^{67}$ When autologous iPSCs-derived dopamine neurons were transplanted in PD model of cynomolgus monkey, the neurons engraft and survive for prolonged time of 2 years leading to improvement in the motor function in the nonhuman primate model. ${ }^{68}$ iPSCs have also been used effectively against HD and ALS by their capability to differentiate into desired neuronal lineages. ${ }^{69,70}$

In spite of the promising in vitro and preclinical studies, the use of iPSCs in clinical trials is still in infant stage. There are some major challenges like tumorigenicity and immunogenicity to be addressed before using iPSCs for clinical applications. iPSCs used for transplantation could lead to teratoma formation: any residual pluripotent stem cells in grafting experiment could induce teratoma. This issue can be addressed by developing more efficient nonintegrative 
approaches for deriving iPSCs, using differentiated cells rather than iPSCs and also by prior screening and selection of cells before transplantation. ${ }^{71}$ For immunogenicity issue, though mostly iPSCs are used in autologous fashion there are some evidences that showed that iPSCs and cells derived from iPSCs can still elicit little immune response in syngeneic recipients that again can be overcome by improved reprogramming technologies. ${ }^{72}$

iPSC applications gain much attention also for autism research. ${ }^{73}$ Successful reprogramming of peripheral bloodderived mononuclear cells from autistic child into iPSCs has been performed by transgene-free delivery system. ${ }^{74}$ Customized iPSCs will help in elucidating the pathogenic mechanisms of ASDs, ${ }^{75}$ also for neuronal differentiation and maturation. ${ }^{76}$ Indeed, iPSC-derived neurons from autistic subjects show aberrant cation channels expression, voltagegated currents, and changes in synaptic functions. ${ }^{77,78}$ Autistic patient-derived stem cells display an altered developmental neuronal phenotype: alteration in cell bodies, branched neurites, and motility compared with those derived from controls. ${ }^{79}$ Using iPSCs to generate three-dimensional models of neurons and brain structures could also be useful to model autism pathophysiology. ${ }^{80}$

\section{Stem cells and autism: animal models}

Animal models are playing a crucial role in exploring the potential of stem cells for developing therapeutic strategies for ASDs and will provide novel insights through which stem cells can help in ameliorating ASD-associated phenotypes. These information cannot be achieved by clinical trials.

As lifelong neurodevelopmental pathologies, ASDs are uniquely human behaviors and animal models fail to fully reproduce the human condition; however, they could provide some important basic information. ${ }^{81} \mathrm{~A}$ commonly used rodent model for ASD is the black and tan brachyuric (BTBR) inbred mouse strain. BTBR mice spontaneously develop behavioral deficits and brain abnormalities reflecting ASDs. Human MSCs were intracerebroventricularly transplanted $(50,000$ cells $/ \mu \mathrm{L})$ in BTBR mice. ${ }^{82}$ Cell therapy improved repetitive behaviors in transplanted mice by means of decreasing digging and self-grooming duration and increasing the latency between two consecutive events. Cell-transplanted mice also displayed decreasing in cognitive rigidity as measured by water T-maze test. To note, social behavior was also improved: transplanted BTBR mice reported better social approach and social novelty preference with respect to nontransplanted BTBR mice. ${ }^{82}$ By a cellular point of view, hMSCs improved hippocampal neurogenesis (increasing of Ki-67 and DCX markers) and increased BDNF levels; after 6 weeks posttransplantation, hMSCs were found to be located close to the wall of the dorsal third ventricle. In the same mouse model, hMSC transplantation $(50,000$ cells $/ \mu \mathrm{L}$ into the cerebral lateral ventricle) showed long-term beneficial effects in ameliorating autistic-like symptoms. ${ }^{83}$ Social behaviors were improved and stereotypic behaviors were reduced at 6 months posttransplantation. Another human stem cell type, the ASCs (50,000 cells $/ \mu \mathrm{L}$, intraventricularly), was successfully used in valproic acid (VPA)-induced autism mouse model ${ }^{84}$ Transplanted mice displayed increased motor coordination (as measured by open-field test) and social behaviors and decreased anxiety. Human ASCs were responsible to increase the phosphatase and tensin homolog, VEGF, IL-10 expression, and p-AKT/AKT ratio in the brains of VPA mice. ${ }^{84}$ Mouse-derived MSCs were used in VPA-induced autism model, resulting in increasing neurogenesis and promoting maturation of newly formed neurons in the dentate gyrus 2 months after transplantation. ${ }^{85}$ MSCs were expanded in culture for up to 20 passages and immunophenotyped for mesenchymal specific markers. Then thousands of MSCs in $5 \mu \mathrm{L}$ MSC were transplanted into the right lateral ventricle. Deficits in cognitive and social behaviors were also improved after 2 weeks posttransplantation. ${ }^{85}$

Beyond stem cell therapy as valuable tool for treating autism, stem cells also offer the possibility for in-depth study of ASD pathology. Offspring of immune-activated mothers (maternal immune activation autism model) develop preferential myeloid lineage potential and altered differentiation of HSCs. ${ }^{86}$ The importance of this work reflects that immune changes during maternal life could confer alterations in stem cells lineage through the entire life of offspring.

Transcriptome analysis revealed differential expressed genes in dental pulp stem cells from idiopathic ASD subjects compared to controls. ${ }^{87}$ While stem cells could be used for understanding the biologic mechanisms of ASDs, the cellular changes of ASD-derived stem cells pose some concerns for autologous cell transplantation, as described further in this review.

\section{Stem cells and autism: clinical trials}

Clinical trials on stem cell transplantation in ASDs are of vital importance to validate safety (in first) and the efficacy of the cellular therapy.

Currently, several clinical trials have been performed to demonstrate safety and efficacy of stem cells autism management (Table 2). Sharma et al conducted an open-label 
Table 2 Clinical trials performed on the use of stem cells in ASDs

\begin{tabular}{|l|l|l|l|l|}
\hline Type of trial & $\begin{array}{l}\text { Number and type of cells } \\
\text { transplanted/source }\end{array}$ & Duration & Primary outcomes & Reference \\
\hline Autologous, open-label & $\begin{array}{l}8.19 \times 10^{7} \text { mononuclear cells/ } \\
\text { bone marrow }\end{array}$ & 26 months & $\begin{array}{l}\text { Safety } \\
\text { Improvements in cognitive and social tasks } \\
\text { Improvement in hypoperfused brain areas }\end{array}$ & 88 \\
\hline $\begin{array}{l}\text { Allogenic, nonrandomized, } \\
\text { open-label, single-center } \\
\text { Phase I/II trial, combined } \\
\text { transplantation }\end{array}$ & $\begin{array}{l}2 \times 10^{6} / \mathrm{kg} \text { mononuclear cells/ } \\
\text { cord blood and I } \times 10^{6} / \\
\mathrm{kg} \text { mesenchymal stem cells/ } \\
\text { umbilical cord }\end{array}$ & 24 weeks & $\begin{array}{l}\text { Safety } \\
\text { Improvements in stereotypic behaviors and } \\
\text { lethargy/social withdrawal }\end{array}$ & 9 I \\
\hline $\begin{array}{l}\text { Allogenic, open-label, } \\
\text { single center }\end{array}$ & $\begin{array}{l}30 \times 10^{6} / \mathrm{mL} \text { fetal stem cells/ } \\
\text { fetus }\end{array}$ & 12 months & $\begin{array}{l}\text { Safety } \\
\text { Improvement in cognitive ability, behaviors, } \\
\text { sociability } \\
\text { Improvements in immune functions }\end{array}$ & 37 \\
\hline $\begin{array}{l}\text { Autologous, randomized, } \\
\text { blinded, placebo- } \\
\text { controlled }\end{array}$ & Umbilical cord & 24 weeks & $\begin{array}{l}\text { Safety } \\
\text { No improvements in symptoms }\end{array}$ & 93 \\
\hline $\begin{array}{l}\text { Autologous, Phase I, } \\
\text { single-center, open-label }\end{array}$ & Umbilical cord & 12 months & $\begin{array}{l}\text { Safety } \\
\text { Improvement in socialization, communication, } \\
\text { and adaptive behavior }\end{array}$ & 94 \\
\hline
\end{tabular}

proof-of-concept study on the use of autologous bone marrow-derived mononuclear cell (BMMNC) transplantation in 32 subjects (median age at intervention 10.5 years, male:female 3:1) with confirmed diagnosis of autism. ${ }^{88}$ The protocol included intrathecal cellular therapy followed by occupational therapy, sensory integrative approach, speech therapy, psychological intervention, and specific dietary recommendations. Mononuclear cell fraction is a heterogeneous mixture consisting of endothelial progenitors, HSCs and MSCs, and multipotent adult progenitor cells. These cells were separated from the aspirate of bone marrow, counted by CD34+ marker and checked for viability. On the same day, the cells were intrathecally injected and methyl prednisolone was given intravenously to enhance survival of the injected cells. Long-term adverse events were monitored to establish the safety of stem cell transplantation. Minor adverse events (vomiting, nausea, pain at side of injection, or aspiration) were present. These events were reported to be procedure-related and not cellular transplantation-related issues. Minimal increase in hyperactivity was recorded as a major adverse event related to cell procedure, along with three patients developing seizures. After cellular therapy, Indian Scale for Assessment of Autism (ISAA) indicated improvements in the domains of social relationships and reciprocity (improved eye contact, social smile, and reaching out to others), cognitive aspects (attention, concentration, and time of response), and also in speech and language patterns (reduction in echolalic speech, engaging in stereotyped repetitive use of language, production of infantile squeals or unusual noises, inability to initiate or sustain conversation with others, inability to grasp the pragmatics of the conversation, and speech regression). Decrease in inappropriate emotional responses, exaggerated emotions, engaging in self-stimulating emotions, and getting excited or agitated for no apparent reason was recorded. CGI scale scored changes in the severity of the disease, overall improvement, and the efficacy of the treatment. Interestingly, functional neuroimaging, by the means of positron emission tomography (PET) scan, showed increased ${ }^{18} \mathrm{~F}$-fluorodeoxyglucose $\left({ }^{18} \mathrm{~F}-\mathrm{FDG}\right)$ uptake in the areas of frontal lobe, cerebellum, amygdala, hippocampus, parahippocampus, and mesial temporal lobe after 6 months of cellular therapy. Hypoperfusion has been recently demonstrated in key brain areas of ASD subjects. ${ }^{89}$ Hypometabolic areas before cell transplantation showed increased metabolism after cellular delivery, probably due to improved oxygenation and functioning of the damaged neurons. As limitations, authors report the small sample size, and the absence of randomization and a control group. ${ }^{88}$

Most recently, Sharma et al performed this type of cellular treatment on a male autistic adult (25 years old). ${ }^{90}$ Autologous BMMNCs were intrathecally transplanted. No major adverse events were seen. After 6 months of cellular therapy, improvements in concentration, sitting tolerance, attention, sleep, eye contact, social interactions, and memory were reported, as measured by ISAA, CARS, and Functional Independence Measure scores before and after cellular treatment. Six months posttherapy, ${ }^{18} \mathrm{~F}-\mathrm{FDG}$ PET scan showed improvements in brain hypometabolism. 
Lv et al performed a Phase I/II trial to investigate the safety and efficacy of combined transplantation of CBMNCs and UCMSCs in treating children with autism. ${ }^{48}$ Thirtyseven autistic children (only one female) were recruited and randomly subdivided in control (mean age 5.60) and experimental groups. This group was further divided into CBMNC group (mean age 7.4) and combined group (mean age 6.2) which received both types of cells. No adverse effects were recorded at the time of transplantation and during the whole follow-up. As minor effects, only five children developed a transiently low-grade fever. About cell procedure, the cells were isolated from gifted cord blood and umbilical cord of informed healthy donors. CD34+ CBMNCs were extracted and in vitro grown in a GMP facility. After extraction from umbilical cord, UCMSCs were in vitro expanded and labeled for MSC characterization: CD29+, CD73+, CD90+, CD105+, the expression of CD45, CD34, CD14, CD79, and HLA-DR was absent or $<2 \%$. Cell viability, sterility, mycoplasma, and endotoxin presence were monitored. The cell transplantation protocol required four times cell administrations in both CBMNC and combination groups at an interval of 5-7 days. ${ }^{48}$ CBMNCs and UCMSCs were transplanted intravenously (20 $\mathrm{mL})$ and/or intrathecally $(2 \mathrm{~mL})$, respectively, per treatment. After cellular therapy, CARS, CGI, and ABC reported significant improvements in stereotypic behaviors and lethargy/ social withdrawal (improvements in visual, emotional and intellectual responses, body use, adaption to change, fear or nervousness, nonverbal communication, hyperactivity, and inappropriate speech). ${ }^{48}$ At the end of 24-week follow-up, best improvements were seen in combination group rather than CBMNC group, with respect to control group. Probably, the CBMNCs and UCMSCs exerted their positive actions synergically. Among limitations, enrolled subjects were not categorized on disease severity and long-term efficacy (beyond 24 weeks) was not evaluated.

In another open-label pilot study, a total of 45 autistic children (39 males, six females, mean age 6.9) were enrolled to assess the safety of the use of FSCs in ASDs. ${ }^{37}$ FSCs were harvested from 5- to 9-week-old human fetuses (one donor sample for each transplantation procedure) following voluntarily selective pregnancy terminations. Donor women and fetal samples were tested for bacterial, fungal, and viral infections and parasites. CD34+ HSCs were extracted from fetal liver (a powerful niche for $\mathrm{HSCs}$ ) ${ }^{91}$ and brain and in vitro expanded. Colony-forming units and neurosphere formation were checked. HSCs were then stored in liquid nitrogen at $-196^{\circ} \mathrm{C}$ in the cryobank and were intravenously transplanted at day 1 . On the second day, the fetal cells were injected into the subcutaneous abdominal adipose tissues. ASD children treated with FSCs displayed no adverse events or side effects due to cell therapy or steroid and antihistamine combination pretreatment during the 1-year follow-up period studied. The early post-cellular transplantation effects observed were improved eye contact, appetite, and socialization. Autism Treatment Evaluation Checklist and $\mathrm{ABC}$ scores at follow-up times of 6 and 12 months showed improvements in sociability, cognitive ability, and behaviors, especially at the final time point. To note, pre- and post-cellular treatment immunologic findings indicated an improved cell-mediated immunity, due to a significant increase of CD3+ $\mathrm{T}$ lymphocytes and CD4+ $\mathrm{T}$ helpers, and a decrease in CD19+ B lymphocytes counts after the cellular treatment (pretreatment values were abnormal). Fetal SC transplantation was safe and well tolerated. According to the authors, the administration routes (intravenous and subcutaneous) were chosen on the basis of their less invasivity. Immunomodulatory functions of FSCs seem to be a key mechanism of action. ${ }^{37}$

Recently, Phase I/II results of a clinical trial on autologous umbilical cord blood (AUCB) transplantation in idiopathic ASD children were published. ${ }^{92}$ As crossover study, ASD children (age 2-7 years), with umbilical cord blood cryopreserved and stored, were transplanted with either AUCB or placebo ( $0.9 \%$ saline solution), and evaluated at baseline, 12 , and 24 weeks. The subjects were randomly divided into two groups. The first group received cord blood infusion and then saline injection. The second group received saline infusion first, then cord blood infusion. Accordingly to the authors, the choice of the crossover study is that in this way each subject serves as its own control. In addition, the crossover design resulted in excellent compliance by parents. Transplanted ASD children were evaluated at 12 and 24 weeks posttransplantation. UCB was checked for sterility, viability, colony-forming unit, and CD34+ cell count. Some possible UCB therapy-associated gastrointestinal disorders were reported. No severe adverse events required treatment. CGI and Expressive/Receptive One Word Picture Vocabulary Tests scores reported minimal evidence of clinical effectiveness of AUCB therapy. While crossover study offers the possibility to minimize the baseline variability, as limitations post-thaw CFU capacity and CD34+ count need to be better addressed. Another point of discussion is the exact AUCB dosage, varying among enrolled subjects due to parental choice in using own biobanked UCB. This latter study shows conflicting results compared to the Dawson study. ${ }^{93}$ Twenty-five ASD children (21 males, four females, mean age 4.6 years) received a single intravenous infusion of AUCB. Sterility, 
infection disease markers, nucleated cell count, CD34+ count, and CFU were tested on biobanked UCB. A portion of or the entire own cord blood unit $\left(1-5 \times 10^{7}\right.$ cells $\left./ \mathrm{kg}\right)$ was infused per ASD subject. AUCB infusion was well tolerated, as no serious adverse effect was reported in any participant. Agitation, allergy, and skin changes were reported as unrelated adverse effects. Vineland Adaptive Behavior Scale-II, CGI, Pervasive Developmental Disorder Behavior Inventory, and Expressive One-Word Picture Vocabulary Test-4 were the main tests used to assess cognitive and behavioral improvements. Socialization, communication, and adaptive behavior scores were improved at 6 months postinfusion and were sustained between 6 and 12 months posttreatment. ${ }^{93}$ Interestingly, nonverbal, higher IQ ASD children showed greater improvements in behaviors. However, as authors stated, the observed behavioral outcomes could be due to the natural course of development during the preschool period.

\section{Limitations}

Several limitations and recommendations have to be taken into account before claiming definitive results about cellular therapy in ASD.

Stem cell therapy offers novel opportunity to develop cell-based drugs and applications to treat several diseases, including immune and neurodegenerative pathologies, ${ }^{94}$ as well as ASD. ${ }^{22}$ It is crucial that cellular therapy is performed under laboratory and clinical guidelines. The International Association of Neurorestoratology has recently published the Clinical Cell Therapy Guidelines for Neurorestoration. ${ }^{95}$ These guidelines issue the recommended standards for personnel, facilities, and institutions that perform cell-based therapies, as well as the ethical requirements, and include the provisions: patient-informed consent/IRB; indications/ contraindications for cell therapy; documentation of procedure and therapy; safety and efficacy evaluations; policy of repeated treatments; not charging patients for unproven therapies; basic principles of cell therapy; and publishing responsibility. ${ }^{95}$ While the mechanisms of action of stem cells are being explained by basic research, as well as by in vivo models, clinical trials provide scientific effectiveness for human applications. ${ }^{96}$ However, from the clinical trials examined above (Table 2), several limitations have to be taken into account, before claiming definitive results for the use of stem cells in ASD treatment.

\section{Relatively small number of subjects}

The number of enrolled subjects requires larger studies on the use of the cell therapy in ASDs. All the analyzed clinical trials admit the small sample size used. Control group also needs to be more standardized.

\section{Time of follow-up}

Harmonization of the time of the study is desirable. Longterm outcomes or the choice of multiple timely transplantations need to be elucidated.

\section{Efficacy}

The efficacy of cell therapies in ASDs should be evaluated by internationally validated, standardized, and preferably harmonized scales. Too many different scales and scores, even if well adopted and established by international scientific community, often do not display the effective result of cell transplantation.

\section{Cell heterogeneity and culturing}

A better characterization of cell types used in all the abovementioned studies will help in the right choice of cell to be utilized. If the cells require in vitro expansion before transplantation remains to be clarified. To note, two clinical studies $^{92,93}$ used part of or entire AUCB. Eventually cellular senescence and life span need more clarification. Senescence of cultured stem cells is another major concern for clinical trials. Prolonged in vitro expansion could trigger senescence phenotype and telomere shortening, in this way the stem cell regenerative capacity could be modified. ${ }^{54}$

\section{Cell source and dosage}

As seen in the studies summarized in Table 2, the cell sources are very different, with significant properties varying from tissue to tissue. Proliferation and expansion potential are affected also by donor age. ${ }^{97}$ The effective cell dosage has to be determined more. The optimal stem cell type for cellular grafts is still uncertain.

\section{Autologous or allogenic transplantation?}

The choice between autologous or allogenic transplantation remains a key factor. ${ }^{98}$ Autologous infusion requires preventive storage of the own biomaterial, with the related issues (ie, the cost for the cryo-storage). In addition, even if some inherited genetic diseases are treated with stem cells (ie, thalassemia major or severe combined immune deficiency [SCID] diseases), ${ }^{99}$ the possibility to treat the cases of ASDs due to genetic defects (nonsyndromic autism) ${ }^{100}$ is still debated. If some genetic modifications are present in the ASD subject, these changes will be kept by all the stored and biobanked cell types. Allogenic transplantation overcomes 
this latter problem. However, the availability of donors and subsequent infectious disease tests are key points to be taken into account.

\section{Route of cell administration}

Intrathecal route seems to be invasive. However, authors who used this way of administration reported its safety and efficient delivery of cells to brain, as transplanted cells could reach critical central nervous system areas through cerebrospinal fluid, enhancing cell homing onto damaged centers. ${ }^{101}$

\section{Ethics}

Ethics in stem cell treatments, as well as in ASD management, require special attention. ${ }^{102}$ Cell therapy must be performed under regulation and approval of regulatory institutions. In the case of negative results from clinical trials, practice of the cell therapy should be discontinued.

Another question is the validity of repeated cell treatments. At this time, there is no published evidence of the effectiveness of repeated cell transplantations in ASDs and clinical trials should be performed. Dawson et al highlight that the economic status could affect cell therapy availability. ${ }^{93}$ Especially in the case of AUCB, some ethnic groups may not be able to deal the cost of biobanking.

\section{Conclusion}

Preclinical evidences highlight potential benefit and important advances for the use of cellular therapy in ASDs. As the mechanisms by which transplantation of stem cells leads to an enhanced functional recovery and structural reorganization have to be better elucidated, ${ }^{61}$ in vivo studies must provide definitive results on the mechanism of action of stem cells that in some cases it is not possible to reproduce or study in humans (ie, detailed analysis of secretome process). Initially, the first theory on mechanism of action of stem cells was that cell therapy could act by a "cell replacement" mechanism; nowadays, large emerging evidences have shown that cell therapy works by providing trophic or "chaperone" support to the injured tissue and brain. ${ }^{103}$ It is noteworthy to consider that the clinical trials on stem cell transplantation in ASD subjects clearly indicate the safety of the procedures (safety is the first outcome). These studies also report significant encouraging positive effects in relief of ASD symptoms (a part of the work of Chez et al, ${ }^{92}$ as mentioned earlier, where the authors claim only for a trend of amelioration) and advocate for the use of cellular therapy in ASDs. However, to date, only five clinical trials have been performed (Table 2) with several differences among them (study design, subjects enrolled, cellular types, route of administration, outcome measures), which will require further examinations. Taken together the limitation considerations and the promising ameliorative effects of cellular therapies in ASD treatment, more complete and exhaustive investigations and large trials will be needed in order to claim definitive results. ${ }^{104}$

\section{Disclosure}

The authors report no conflicts of interest in this work.

\section{References}

1. Courchesne E, Pramparo T, Gazestani VH, Lombardo MV, Pierce K, Lewis NE. The ASD living biology: from cell proliferation to clinical phenotype. Mol Psychiatry. Epub 2018 June 22.

2. Geschwind DH. Advances in autism. Annu Rev Med. 2009;60: 367-380.

3. Chaste P, Leboyer M. Autism risk factors: genes, environment, and gene-environment interactions. Dialogues Clin Neurosci. 2012;14(3):281-292.

4. Mottron L, Belleville S, Rouleau GA, Collignon O. Linking neocortical, cognitive, and genetic variability in autism with alterations of brain plasticity: the Trigger-Threshold-Target model. Neurosci Biobehav Rev. 2014;47:735-752.

5. Iovene MR, Bombace F, Maresca R, et al. Intestinal dysbiosis and yeast isolation in stool of subjects with autism spectrum disorders. Mycopathologia. 2017;182(3-4):349-363.

6. Rose DR, Yang H, Serena G, et al. Differential immune responses and microbiota profiles in children with autism spectrum disorders and co-morbid gastrointestinal symptoms. Brain Behav Immun. 2018;70:354-368.

7. Onore C, Careaga M, Ashwood P. The role of immune dysfunction in the pathophysiology of autism. Brain Behav Immun. 2012;26(3):383-392.

8. Siniscalco D, Schultz S, Brigida AL, Antonucci N. Inflammation and neuro-immune dysregulations in autism spectrum disorders. Pharmaceuticals (Basel). 2018;11(2):E56.

9. Ghaziuddin M, Al-Owain M. Autism spectrum disorders and inborn errors of metabolism: an update. Pediatr Neurol. 2013;49(4):232-236.

10. Baio J, Wiggins L, Christensen DL, et al. Prevalence of autism spectrum disorder among children aged 8 years - autism and developmental disabilities monitoring network, 11 sites, united states, 2014. MMWR. Surveill Summ. 2018;67(6):1-23.

11. Elsabbagh M, Divan G, Koh YJ, et al. Global prevalence of autism and other pervasive developmental disorders. Autism Res. 2012;5(3):160-179.

12. American Psychiatric Association. Diagnostic and Statistical Manual of Mental Disorders. 5th ed. Washington DC: American Psychiatric Association; 2013.

13. Pratt J, Hall J. Biomarkers in neuropsychiatry: a prospect for the twentyfirst Century? Curr Top Behav Neurosci. Epub 2018 Jul 3. (7):1-8.

14. Thibaut F. New perspectives in autism spectrum disorders. Dialogues Clin Neurosci. 2017;19(4):323.

15. Oberman LM, Rotenberg A, Pascual-Leone A. Use of transcranial magnetic stimulation in autism spectrum disorders. $J$ Autism Dev Disord. 2015;45(2):524-536.

16. Rossignol DA, Bradstreet JJ, Van Dyke K, et al. Hyperbaric oxygen treatment in autism spectrum disorders. Med Gas Res. 2012;2(1):16.

17. Sharma SR, Gonda X, Tarazi FI. Autism spectrum disorder: classification, diagnosis and therapy. Pharmacol Ther. 2018;190:91-104. 
18. DemMayo MM, Song YJC, Hickie IB, Guastella AJ. A review of the safety, efficacy and mechanisms of delivery of nasal oxytocin in children: therapeutic potential for autism and Prader-Willi syndrome, and recommendations for future research. Paediatr Drugs. 2017;19(5):391-410.

19. Gasparotto FM, Dos Reis Lívero FA, Tolouei Menegati SEL, Junior AG. Herbal medicine as an alternative treatment in autism spectrum disorder: a systematic review. Curr Drug Metab. 2018;19(5):454-459.

20. Adams JB, Audhya T, Geis E, et al. Comprehensive nutritional and dietary intervention for autism spectrum disorder-a randomized, controlled 12-month trial. Nutrients. 2018;10(3):E369.

21. Benger M, Kinali M, Mazarakis ND. Autism spectrum disorder: prospects for treatment using gene therapy. Mol Autism. 2018;9:39.

22. Siniscalco D, Bradstreet JJ, Sych N, Antonucci N. Perspectives on the use of stem cells for autism treatment. Stem Cells Int. 2013;2013:262438.

23. Song CG, Zhang YZ, Wu HN, et al. Stem cells: a promising candidate to treat neurological disorders. Neural Regen Res. 2018;13(7):1294-1304.

24. Mazzini L, Ferrari D, Andjus PR, et al; BIONECA COST ACTION WG Neurology. Advances in stem cell therapy for amyotrophic lateral sclerosis. Expert Opin Biol Ther. 2018;18(8):865-881.

25. Brick DJ, Nethercott HE, Montesano S, et al. The autism spectrum disorders stem cell resource at Children's Hospital of Orange County: implications for disease modeling and drug discovery. Stem Cells Transl Med. 2014;3(11):1275-1286.

26. Siniscalco D, Mijatovic T, Bosmans E, et al. Decreased numbers of CD57+CD3- cells identify potential innate immune differences in patients with autism spectrum disorder. In Vivo. 2016;30(2):83-89.

27. Inga Jácome MC, Morales Chacòn LM, Vera Cuesta H, et al. Peripheral inflammatory markers contributing to comorbidities in autism. Behav Sci (Basel). 2016;6(4):E29.

28. Brigida AL, Schultz S, Cascone M, Antonucci N, Siniscalco D. Endocannabinod signal dysregulation in autism spectrum disorders: a correlation link between inflammatory state and neuro-immune alterations. Int J Mol Sci. 2017;18(7):E1425.

29. Siniscalco D, Sapone A, Giordano C, et al. The expression of caspases is enhanced in peripheral blood mononuclear cells of autism spectrum disorder patients. J Autism Dev Disord. 2012;42(7):1403-1410.

30. Siniscalco D, Sapone A, Giordano C, et al. Cannabinoid receptor type 2 , but not type 1 , is up-regulated in peripheral blood mononuclear cells of children affected by autistic disorders. J Autism Dev Disord. 2013;43(11):2686-2695.

31. Caprnda M, Kubatka P, Gazdikova K, et al. Immunomodulatory effects of stem cells: therapeutic option for neurodegenerative disorders. Biomed Pharmacother. 2017;91:60-69.

32. Siniscalco D, Giordano C, Galderisi U, et al. Long-lasting effects of human mesenchymal stem cell systemic administration on pain-like behaviors, cellular, and biomolecular modifications in neuropathic mice. Front Integr Neurosci. 2011;5:79.

33. Guillot PV, Gotherstrom C, Chan J, Kurata H, Fisk NM. Human first-trimester fetal MSC express pluripotency markers and grow faster and have longer telomeres than adult MSC. Stem Cells. 2007;25(3):646-654.

34. Lee H, Yun S, Kim IS, et al. Human fetal brain-derived neural stem/ progenitor cells grafted into the adult epileptic brain restrain seizures in rat models of temporal lobe epilepsy. PLoS One. 2014;9(8):e104092.

35. Kelly S, Bliss TM, Shah AK, et al. Transplanted human fetal neural stem cells survive, migrate, and differentiate in ischemic rat cerebral cortex. Proc Natl Acad Sci U S A. 2004;101(32):11839-11844.

36. Freed CR, Greene PE, Breeze RE, et al. Transplantation of embryonic dopamine neurons for severe Parkinson's disease. $N$ Engl J Med. 2001;344(10):710-719.

37. Bradstreet JJ, Sych N, Antonucci N, et al. Efficacy of fetal stem cell transplantation in autism spectrum disorders: an open-labeled pilot study. Cell Transplant. 2014;23(1 Suppl):S105-S112.

38. Dominici M, Le Blanc K, Mueller I, et al. Minimal criteria for defining multipotent mesenchymal stromal cells. The International Society for Cellular Therapy position statement. Cytotherapy. 2006;8(4):315-317.
39. Giordano A, Galderisi U, Marino IR. From the laboratory bench to the patient's bedside: an update on clinical trials with mesenchymal stem cells. J Cell Physiol. 2007;211(1):27-35.

40. Katuchova J, Harvanova D, Spakova T, et al. Mesenchymal stem cells in the treatment of type 1 diabetes mellitus. Endocr Pathol. 2015;26(2):95-103.

41. Siniscalco D, Bradstreet JJ, Sych N, Antonucci N. Mesenchymal stem cells in treating autism: Novel insights. World J Stem Cells. 2014;6(2):173-178.

42. Liang CM, Weng SJ, Tsai TH, et al. Neurotrophic and neuroprotective potential of human limbus-derived mesenchymal stromal cells. Cytotherapy. 2014;16(10):1371-1383.

43. Klyushnenkova E, Mosca JD, Zernetkina V, et al. T cell responses to allogeneic human mesenchymal stem cells: immunogenicity, tolerance, and suppression. J Biomed Sci. 2005;12(1):47-57.

44. Jacobs SA, Roobrouck VD, Verfaillie CM, Van Gool SW. Immunological characteristics of human mesenchymal stem cells and multipotent adult progenitor cells. Immunol Cell Biol. 2013;91(1):32-39.

45. Siniscalco D, Sapone A, Cirillo A, Giordano C, Maione S, Antonucci $\mathrm{N}$. Autism spectrum disorders: is mesenchymal stem cell personalized therapy the future? J Biomed Biotechnol. 2012;2012:480289.

46. Kassis I, Vaknin-Dembinsky A, Karussis D. Bone marrow mesenchymal stem cells: agents of immunomodulation and neuroprotection. Curr Stem Cell Res Ther. 2011;6(1):63-68.

47. Karussis D, Petrou P, Kassis I. Clinical experience with stem cells and other cell therapies in neurological diseases. J Neurol Sci. 2013;324(1-2):1-9.

48. Lv YT, Zhang Y, Liu M, et al. Transplantation of human cord blood mononuclear cells and umbilical cord-derived mesenchymal stem cells in autism. J Transl Med. 2013;11:196.

49. Bourin P, Bunnell BA, Casteilla L, et al. Stromal cells from the adipose tissue-derived stromal vascular fraction and culture expanded adipose tissue-derived stromal/stem cells: a joint statement of the International Federation for Adipose Therapeutics and Science (IFATS) and the International Society for Cellular Therapy (ISCT). Cytotherapy. 2013;15(6):641-648.

50. Frese L, Dijkman PE, Hoerstrup SP. Adipose tissue-derived stem cells in regenerative medicine. Transfus Med Hemother. 2016;43(4): 268-274.

51. Zhou F, Gao S, Wang L, et al. Human adipose-derived stem cells partially rescue the stroke syndromes by promoting spatial learning and memory in mouse middle cerebral artery occlusion model. Stem Cell Res Ther. 2015;6:92.

52. Ding DC, Chang YH, Shyu WC, Lin SZ. Human umbilical cord mesenchymal stem cells: a new era for stem cell therapy. Cell Transplant. 2015;24(3):339-347.

53. Xu Y, Huang S, Ma K, Fu X, Han W, Sheng Z. Promising new potential for mesenchymal stem cells derived from human umbilical cord Wharton's jelly: sweat gland cell-like differentiative capacity. JTissue Eng Regen Med. 2012;6(8):645-654.

54. Alessio N, Pipino C, Mandatori D, et al. Mesenchymal stromal cells from amniotic fluid are less prone to senescence compared to those obtained from bone marrow: an in vitro study. $J$ Cell Physiol. 2018;233(11):8996-9006.

55. Witkowska-Zimny M, Wrobel E. Perinatal sources of mesenchymal stem cells: Wharton's jelly, amnion and chorion. Cell Mol Biol Lett. 2011;16(3):493-514.

56. Stevens HE, Smith KM, Rash BG, Vaccarino FM. Neural stem cell regulation, fibroblast growth factors, and the developmental origins of neuropsychiatric disorders. Front Neurosci. 2010;4:59.

57. Reynolds BA, Weiss S. Generation of neurons and astrocytes from isolated cells of the adult mammalian central nervous system. Science. 1992;255(5052):1707-1710.

58. Palmer TD, Ray J, Gage FH. FGF-2-responsive neuronal progenitors reside in proliferative and quiescent regions of the adult rodent brain. Mol Cell Neurosci. 1995;6(5):474-486.

59. Buxbaum JD. Multiple rare variants in the etiology of autism spectrum disorders. Dialogues Clin Neurosci. 2009;11(1):35-43. 
60. Hsu YC, Lee DC, Chiu IM. Neural stem cells, neural progenitors, and neurotrophic factors. Cell Transplant. 2007;16(2):133-150.

61. Kim SU, de Vellis J. Stem cell-based cell therapy in neurological diseases: a review. $J$ Neurosci Res. 2009;87(10):2183-2200.

62. Liu SP, Fu RH, Huang SJ, et al. Stem cell applications in regenerative medicine for neurological disorders. Cell Transplant. 2013;22(4):631-637.

63. Siniscalco D, Bradstreet JJ, Antonucci N. Therapeutic role of hematopoietic stem cells in autism spectrum disorder-related inflammation. Front Immunol. 2013;4:140.

64. Brigida AL, Siniscalco D. Induced pluripotent stem cells as a cellular model for studying Down Syndrome. J Stem Cells Regen Med. 2016;12(2):54-60.

65. Park IH, Arora N, Huo H, et al. Disease-specific induced pluripotent stem cells. Cell. 2008;134(5):877-886.

66. Medvedev SP, Shevchenko AI, Zakian SM. Induced pluripotent stem cells: problems and advantages when applying them in regenerative medicine. Acta Naturae. 2010;2(2):18-28.

67. Nori S, Okada Y, Yasuda A, et al. Grafted human-induced pluripotent stem-cell-derived neurospheres promote motor functional recovery after spinal cord injury in mice. Proc Natl Acad Sci U S A. 2011;108(40):16825-16830.

68. Hallett PJ, Deleidi M, Astradsson A, et al. Successful function of autologous iPSC-derived dopamine neurons following transplantation in a non-human primate model of Parkinson's disease. Cell Stem Cell. 2015;16(3):269-274

69. Jeon I, Choi C, Lee N, et al. In vivo roles of a patient-derived induced pluripotent stem cell line (HD72-iPSC) in the YAC128 model of Huntington's disease. Int J Stem Cells. 2014;7(1):43-47.

70. Nizzardo M, Simone C, Rizzo F, et al. Minimally invasive transplantation of iPSC-derived ALDHhiSSCloVLA4+ neural stem cells effectively improves the phenotype of an amyotrophic lateral sclerosis model. Hum Mol Genet. 2014;23(2):342-354.

71. Knoepfler PS. Deconstructing stem cell tumorigenicity: a roadmap to safe regenerative medicine. Stem Cells. 2009;27(5):1050-1056.

72. Zhao T, Zhang ZN, Rong Z, Xu Y. Immunogenicity of induced pluripotent stem cells. Nature. 2011;474(7350):212-215.

73. Ben-Reuven L, Reiner O. Modeling the autistic cell: iPSCs recapitulate developmental principles of syndromic and nonsyndromic ASD. Dev Growth Differ. 2016;58(5):481-491.

74. Varga E, Nemes C, Bock I, et al. Establishment of an induced pluripotent stem cell (iPSC) line from a 9-year old male with autism spectrum disorder (ASD). Stem Cell Res. 2017;21:19-22.

75. Lim CS, Yang JE, Lee YK, Lee K, Lee JA, Kaang BK. Understanding the molecular basis of autism in a dish using hiPSCs-derived neurons from ASD patients. Mol Brain. 2015;8(1):57.

76. Kim DS, Ross PJ, Zaslavsky K, Ellis J. Optimizing neuronal differentiation from induced pluripotent stem cells to model ASD. Front Cell Neurosci. 2014;8:109.

77. Griesi-Oliveira K, Acab A, Gupta AR, et al. Modeling non-syndromic autism and the impact of TRPC6 disruption in human neurons. Mol Psychiatry. 2015;20(11):1350-1365.

78. Liu X, Campanac E, Cheung HH, et al. Idiopathic autism: cellular and molecular phenotypes in pluripotent stem cell-derived neurons. Mol Neurobiol. 2017;54(6):4507-4523.

79. Kathuria A, Nowosiad P, Jagasia R, et al. Stem cell-derived neurons from autistic individuals with SHANK3 mutation show morphogenetic abnormalities during early development. Mol Psychiatry. 2018;23(3):735-746

80. Nestor MW, Phillips AW, Artimovich E, Nestor JE, Hussman JP, Blatt GJ. Human inducible pluripotent stem cells and autism spectrum disorder: emerging technologies. Autism Res. 2016;9(5):513-535.

81. Tania M, Khan MA, Xia K. Recent advances in animal model experimentation in autism research. Acta Neuropsychiatr. 2014;26(5):264-271.

82. Segal-Gavish H, Karvat G, Barak N, et al. Mesenchymal stem cell transplantation promotes neurogenesis and ameliorates autism related behaviors in BTBR mice. Autism Res. 2016;9(1):17-32.
83. Perets N, Segal-Gavish H, Gothelf $\mathrm{Y}$, et al. Long term beneficial effect of neurotrophic factors-secreting mesenchymal stem cells transplantation in the BTBR mouse model of autism. Behav Brain Res. 2017;331:254-260.

84. Ha S, Park H, Mahmood U, Ra JC, Suh YH, Chang KA. Human adipose-derived stem cells ameliorate repetitive behavior, social deficit and anxiety in a VPA-induced autism mouse model. Behav Brain Res. 2017;317:479-484.

85. Gobshtis N, Tfilin M, Wolfson M, Fraifeld VE, Turgeman G. Transplantation of mesenchymal stem cells reverses behavioural deficits and impaired neurogenesis caused by prenatal exposure to valproic acid. Oncotarget. 2017;8(11):17443-17452.

86. Hsiao EY, McBride SW, Chow J, Mazmanian SK, Patterson $\mathrm{PH}$. Modeling an autism risk factor in mice leads to permanent immune dysregulation. Proc Natl Acad Sci U S A. 2012;109(31): 12776-12781.

87. Griesi-Oliveira K, Sunaga DY, Alvizi L, Vadasz E, Passos-Bueno MR. Stem cells as a good tool to investigate dysregulated biological systems in autism spectrum disorders. Autism Res. 2013;6(5):354-361.

88. Sharma A, Gokulchandran N, Sane H, et al. Autologous bone marrow mononuclear cell therapy for autism: an open label proof of concept study. Stem Cells Int. 2013;2013:623875.

89. Bjørklund G, Kern JK, Urbina MA, et al. Cerebral hypoperfusion in autism spectrum disorder. Acta Neurobiol Exp (Wars). 2018;78(1): 21-29.

90. Sharma A, Gokulchandran N, Sane H, et al. Therapeutic effects of cellular therapy in a case of adult autism spectrum of disorder. Int Biol Biomed J. 2018;4(2):98-103.

91. Gao S, Liu F. Fetal liver: an ideal niche for hematopoietic stem cell expansion. Sci China Life Sci. 2018;61(8):885-892.

92. Chez M, Lepage C, Parise C, Dang-Chu A, Hankins A, Carroll M. Safety and observations from a placebo-controlled, crossover study to assess use of autologous umbilical cord blood stem cells to improve symptoms in children with autism. Stem Cells Transl Med. 2018;7(4):333-341.

93. Dawson G, Sun JM, Davlantis KS, et al. Autologous cord blood infusions are safe and feasible in young children with autism spectrum disorder: results of a single-center Phase I open-label trial. Stem Cells Transl Med. 2017;6(5):1332-1339.

94. Siniscalco D, Pandolfi A, Galderisi U. State-of-the-art on basic and applied stem cell therapy; Stem Cell Research Italy-International Society for Cellular Therapy Europe. Stem Cells Dev. 2012;21(5): 668-669.

95. Huang H, Young W, Chen L, et al. Clinical cell therapy guidelines for neurorestoration (IANR/CANR 2017). Cell Transplant. 2018;27(2):310-324.

96. Siniscalco D, Giordano A, Galderisi U. Novel insights in basic and applied stem cell therapy. J Cell Physiol. 2012;227(5):2283-2286.

97. Squillaro T, Peluso G, Galderisi U. Clinical trials with mesenchymal stem cells: an update. Cell Transplant. 2016;25(5):829-848.

98. Harousseau JL. Role of stem cell transplantation. Hematol Oncol Clin North Am. 2007;21(6):1157-1174, x.

99. Steward CG, Jarisch A. Haemopoietic stem cell transplantation for genetic disorders. Arch Dis Child. 2005;90(12):1259-1263.

100. Caglayan AO. Genetic causes of syndromic and non-syndromic autism. Dev Med Child Neurol. 2010;52(2):130-138.

101. Sharma A, Gokulchandran N, Chopra G, et al. Administration of autologous bone marrow-derived mononuclear cells in children with incurable neurological disorders and injury is safe and improves their quality of life. Cell Transplant. 2012;21(Suppl 1):S79-S90.

102. Siniscalco D, Di Marsilio A, Antonucci N. Ethics in autism care. Autism. 2013;3:e119.

103. Hess DC, Borlongan CV. Stem cells and neurological diseases. Cell Prolif. 2008;41(Suppl 1):94-114.

104. Siniscalco D, Bradstreet JJ, Antonucci N. The promise of regenerative medicine and stem cell research for the treatment of autism. J Regen Med. 2012;1(1). 
Stem Cells and Cloning: Advances and Applications is an international, peer-reviewed, open access journal. Areas of interest in stem cell research include: Embryonic cell stems; Adult stem cells; Blastocysts; Cordblood stem cells; Stem cell transformation and culture; Therapeutic cloning; Umbilical cord blood and bone marrow cells; Laboratory, animal and human therapeutic studies; Philosophical and ethical issues related to stem cell research. This journal is indexed on CAS. The manuscript management system is completely online and includes a quick and fair peer-review system. Visit http://www.dovepress.com/ testimonials.php to read real quotes from published authors..

Submit your manuscript here: https://www.dovepress.com/stem-cells-and-cloning-advances-and-applications-journal 